\title{
sensors
}

ISSN 1424-8220

(C) 2004 by MDPI

http://www.mdpi.net/sensors

\section{Supermolecular Interaction of Ferrocenium with Yeast DNA and Application in Electrochemical Sensing for Hybridization Recognition of Yeast DNA}

\author{
Huangxian Ju*, Baofen Ye and Jiayin Gu \\ Department of Chemistry, State Key Laboratory of Coordination Chemistry, Institute of Chemical \\ Biology, Nanjing University, Nanjing 210093, China, Fax: +86-25-3593593, Tel: +86-25-3593593 \\ * Author to whom correspondence should be addressed. E-mail: hxju@nju.edu.cn \\ Received: 30 April 2004 / Accepted: 30 May 2004 / Published: 20 July 2004
}

\begin{abstract}
The supermolecular interactions of single-stranded yeast DNA (ssDNA) and double-stranded DNA (dsDNA) with ferrocenium $\left(\mathrm{Fc}^{+}\right)$both in solution and at the electrode/solution interface were studied with UV spectroscopy and electrochemical method. The interaction of covalently immobilized dsDNA with $\mathrm{Fc}^{+}$resulted in a change of the electrode behavior from diffusion-controlled to surface-controlled and an increase in the current response of $\mathrm{Fc}^{+}$reduction, which has been used to develop a novel electrochemical yeast DNA sensor for hybridization recognition of immobilized yeast ssDNA to its complementary ssDNA (cDNA). The adsorption constants of $\mathrm{Fc}^{+}$on ssDNA and dsDNA modified gold electrode surface were $(3.38 \pm 0.04) \times 10^{3} \mathrm{M}^{-1}$ and $(2.02 \pm 0.02) \times 10^{4} \mathrm{M}^{-1}$, respectively, indicating a higher affinity of dsDNA to $\mathrm{Fc}^{+}$. UV spectra and the influence of ion strength showed that the interaction mode between $\mathrm{Fc}^{+}$and dsDNA in solution might be a groove binding. The interaction between $\mathrm{Fc}^{+}$and immobilized DNA was mainly an electrostatic model.
\end{abstract}

Keywords: DNA Biosensors, supermolecular interaction, yeast DNA, ferrocenium, hybridization recognition. 


\section{Introduction}

DNA biosensors have become an important research area during the past several years [1-6]. Various techniques, aiming at fast detecting the hybridization between a probe DNA and a target DNA, have been developed [7-9]. Among them, electrochemical biosensors [10,11], which combine the analytical ability of electrochemical methods with the specificity of the biological recognition process, have received considerable attention. In electrochemical DNA sensors, DNA hybridization is introduced to the electrode surface and detected with an electroactive indicator. These methods rely on the immobilization of an ssDNA probe on the electrode surface. Several methods for the immobilization have been used in the preparation of DNA sensors, including chemical adsorption [12,13] and covalent bonding [14-16]. Recently, new immobilization techniques such as avidin-biotin system [17] and chitosan-modified electrode [18], and covalent binding through molecular self-assembly [19] have become a popular method, due to its simplicity, versatility, high level of orientation and the prevention of the nonspecific adsorption of long DNA chain on the electrode surface. By the molecular self-assembly, ssDNA can be covalently immobilized on the molecular self-assembled modified electrode. The self-assembled monolayer (SAM) modified electrode establishes a stable, highly dense and orientable ssDNA modified monolayer, which can be used for molecular recognition. Millan and Mikkelsen [20] described a sequence-selective biosensor using a DNA-modified SAM glassy carbon electrode with water-soluble carbodiimide (EDC) and N-hydroxysuccinimide (NHS) as coupling reagent and $\mathrm{Co}(\mathrm{pby})_{3}{ }^{3+}$ as electroactive hybridization indicator. Hashimoto et al. [21] reported that a 20-mer ssDNA was immobilized on a gold electrode at a site of 5' end through a mercaptohexyl group and got a higher sensitive sequence-specific DNA electrochemical sensor. In this paper, the native yeast ssDNA was immobilized on a 2-mercaptoethylamine SAM modified gold electrode surface by covalent binding with the help of water-soluble EDC. This method to immobilize ssDNA is relatively convenient and avoids the chemical derivatization of DNA, which is tedious, time-consuming and costly. The 2-mercaptoethylamine SAM serves the dual functions of removing the non-specifically absorbed DNA from the gold and orientating the end point immobilized DNA.

The electroactive indicators used in DNA hybridization sensors generally include two kinds: metal complexes such as $\mathrm{Os}$ [22], $\mathrm{Ru}$ [23] and $\mathrm{Co}$ [24] complexes with aromatic ligands and organic compounds such as Hoechst 33258 [25], acridine dyes [26] and methylene blue [27]. This paper work uses the ferrocenium cation $\left(\mathrm{Fc}^{+}\right)$to achieve the electrochemical transduction of DNA hybridization at a gold electrode surface. $\mathrm{Fc}^{+}$is a cation of the Fe complex with two cyclopentadiene ligands. Fang's group [28,29] has reported a DNA hybridization biosensor using ferrocene derivatives to label the DNA chain. In our experiment, $\mathrm{Fc}^{+}$is used directly as the electrochemical indicator, which avoids the tedious procedures to synthesize the derivatives, to label the derivatives to the DNA chain and to separate the product. $\mathrm{Fc}^{+}$interacts with yeast ssDNA and dsDNA in different ways and shows different 
voltammetric signals, indicating that $\mathrm{Fc}^{+}$is a propriety indicator. The $\mathrm{Fc}^{+}$interacts with the dsDNA in solution by a groove-binding model and the dsDNA immobilized electrode surface in a model-containing electrostatic binding. A sequence-selective DNA biosensor was developed based on a yeast ssDNA-2- mercaptoethylamine SAM modified gold electrode prepared with water-soluble EDC as coupling reagent and $\mathrm{Fc}^{+}$as electroactive indicator.

\section{Experimental}

\section{Reagents and materials}

N-(3-dimethylaminopropyl)-N'-ethylcarbodiimide hydrochloride (EDC, Schuchardt), tris-(hydroxymethyl)aminomethane (Tris, Sigma), 2-mercaptoethylamine (Sigma), and ferrocemium hexafluorophophate $\left(\mathrm{FcPF}_{6}\right.$, Aldrich) were used without further purification. Yeast DNA $\left(1.35 \times 10^{7}\right.$ base pairs, Shanghai Changyang Pharmaceutical Factory) and calf thymus DNA (Sigma) were used as received. Yeast DNA solution (ca. $7.45 \times 10^{-5} \mathrm{M}$ in nucleotide phosphate) containing $50 \mathrm{mM} \mathrm{NaCl}$ and $5 \mathrm{mM}$ Tris at $\mathrm{pH} 7.1$ gave an $\mathrm{A}_{260} / \mathrm{A}_{280}$ (absorbance at 260 and $280 \mathrm{~nm}$, respectively) ratio of 1.9, which indicated that the DNA was sufficiently pure. The denatured ssDNA was obtained by heating native dsDNA in a $100{ }^{\circ} \mathrm{C}$ water bath for $10 \mathrm{~min}$ and then rapidly cooling in an ice-water bath. Other reagents were commercially available and were of analytical grade. Double-distilled water was used in all experiments.

\section{Preparation of DNA sensors}

Gold electrodes were prepared by sealing polycrystalline gold wires ( $>99.99 \%)$ in soft glass tubes. The gold electrodes were abraded with finer grades of SiC paper and polished to a mirror-like surface with 0.3 and $0.05 \mu \mathrm{m}$ alumina suspension. After dipped into $\mathrm{HNO}_{3}(1: 1)$ for $30 \mathrm{~min}$, the electrode was washed with water and then, cleaned ultrasonically for $2 \mathrm{~min}$. The self-assembled monolayer of 2-mercaptoethylamine named as $\mathrm{SAM} / \mathrm{Au}$, shown in Fig. 1, was firstly prepared by soaking a freshly treated electrode in $5 \mathrm{~mL} 5.0 \mathrm{mmol} / \mathrm{L}$ solution of 2-mercaptoethylamine for $10-12 \mathrm{~h}$ at $25{ }^{\circ} \mathrm{C}$. The obtained electrode was thoroughly washed with ethanol and water to remove the physically adsorbed 2-mercaptoethylamine, and was dried in air.

The SAM/Au electrode was incubated in TE buffer solution (10 mM Tris + 1.0 mM EDTA, pH 8.0) containing $10 \mathrm{mM}$ EDC and $1.0 \mathrm{mg} \mathrm{mL}^{-1}$ yeast ssDNA for $3 \mathrm{~h}$ at $25^{\circ} \mathrm{C}$. After it was washed with washing solution $\left(0.4 \mathrm{M} \mathrm{NaOH}+0.25 \% \mathrm{SDS}, 40{ }^{\circ} \mathrm{C}\right)$ for $5 \mathrm{~min}$, an ssDNA-modified electrode (ssDNA/SAM/Au) was obtained.

The ssDNA/SAM/Au was further hybridized with $1.0 \mathrm{mg} \mathrm{mL}^{-1} \mathrm{cDNA}$ (the same heat-denatured yeast ssDNA) in $2 \times \mathrm{SSC}$ buffer $(0.3 \mathrm{M} \mathrm{NaCl}+30 \mathrm{mM}$ sodium citrate solution, $\mathrm{pH} 7.0)$ with stirring for $1 \mathrm{~h}$ at $50{ }^{\circ} \mathrm{C}$ and then cooling gradually to room temperature. These treatments allowed the specific 
sequence cDNA to hybridize with immobilized ssDNA to form dsDNA on the surface of gold electrode (dsDNA/SAM/Au). The obtained dsDNA modified electrode was washed with water and stored at $4{ }^{\circ} \mathrm{C}$ in the TE buffer solution. The procedure of ssDNA immobilization on the gold electrode and hybridization with cDNA was shown in Fig. 1.

The control experiments of ssDNA immobilization were performed with the above-mentioned process without EDC in the solution. Besides complementary yeast ssDNA, the ssDNA/SAM/Au was hybridized with the heat-denatured calf thymus ssDNA as control.

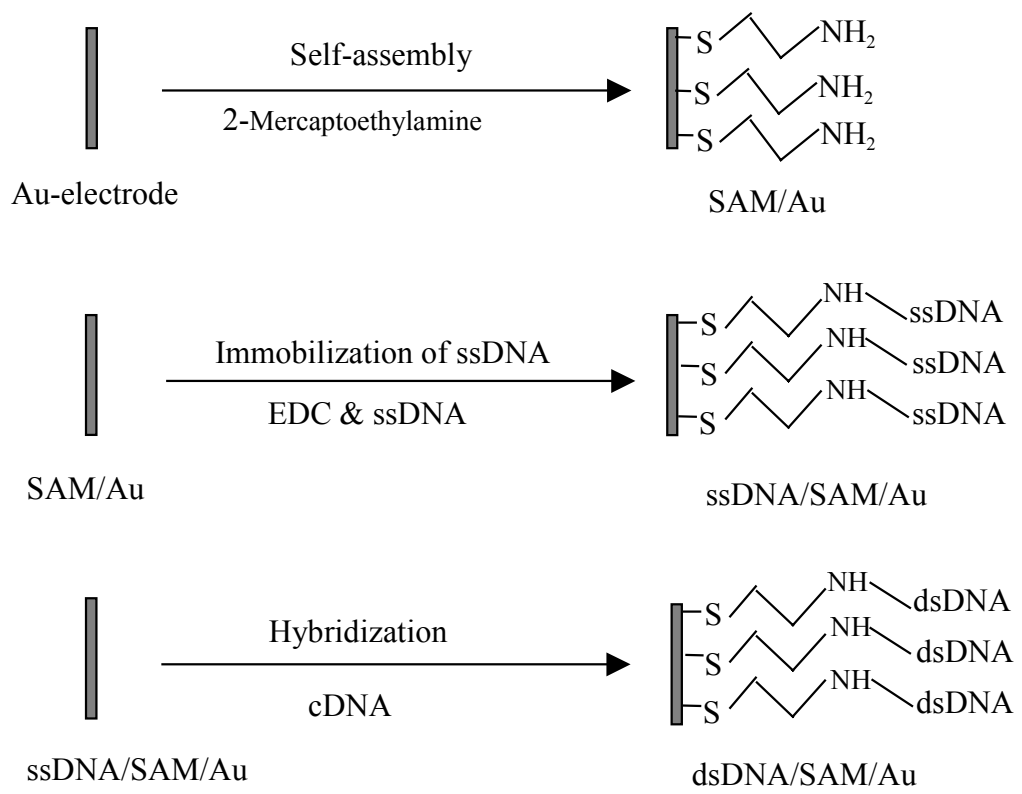

Figure 1. The preparation procedure of DNA sensor.

\section{Apparatus and measurements}

Electrochemical experiments were carried out with a BAS-100B electrochemical analyzer (BAS Inc, USA) and a standard three-electrode system comprising a modified gold electrode with a diameter of $0.5 \mathrm{~mm}$ as working electrode, a $\mathrm{Ag} / \mathrm{AgCl}(3 \mathrm{M} \mathrm{NaCl})$ electrode as reference electrode and a platinum wire as counter electrode. Unless otherwise stated, all cyclic voltammetric experiments were performed in $10 \mathrm{mM}$ Tris $+1.0 \mathrm{mM}$ EDTA buffer (pH 8.0) in a $10 \mathrm{~mL}$ electrochemical cell at $200 \mathrm{mV}$ $\mathrm{s}^{-1}$ at $25{ }^{\circ} \mathrm{C}$. UV spectra were recorded on a UV-3100 spectrophotometer (Japan).

The double-layer capacitance of each electrode was measured using cyclic voltammetry in $1.0 \mathrm{M}$ $\mathrm{KNO}_{3}$ between $+0.4 \mathrm{~V}$ and $+0.6 \mathrm{~V}$. The charging current at $+500 \mathrm{mV}$ was recorded and was plotted versus scan rate $\left(<100 \mathrm{mV} \mathrm{s}^{-1}\right)$. The slope of the plot was the apparent double-layer capacitance. The real area of the gold electrodes was calculated from the cyclic voltammograms in $0.10 \mathrm{M} \mathrm{H}_{2} \mathrm{SO}_{4}$ between 0 and $+1.5 \mathrm{~V}$ by integration of the cathodic peak during the reduction of the superficial gold oxide. The charge of $0.386 \mathrm{mC} / \mathrm{cm}^{2}$ is accepted as the charge necessary to form $\mathrm{Au}_{2} \mathrm{O}_{3}$ [30]. 


\section{Results and Discussion}

\section{Interaction between $\mathrm{Fc}^{+}$and yeast $\mathrm{Ss} D \mathrm{NA}$ or $\mathrm{dsDNA}$}

The cyclic voltammogram of $4.0 \times 10^{-4} \mathrm{M} \mathrm{FcPF}_{6}$ at $200 \mathrm{mV} \mathrm{s}^{-1}$ showed a couple of redox peaks at +164 and $+262 \mathrm{mV}$, respectively (curve A in Fig. 2). Upon addition of $0.5 \mathrm{mg} \mathrm{ml}^{-1}$ ssDNA or dsDNA, the cathodic peak current of $\mathrm{Fc}^{+}$decreased by $15.8 \%$ and $42.1 \%$, respectively, as shown in Table 1 . The decrease in the peak current resulted from the decrease of the free $\mathrm{Fc}^{+}$concentration due to the formation of $\mathrm{Fc}^{+}$-ssDNA or $\mathrm{Fc}^{+}$-dsDNA and the lower diffusion coefficients of $\mathrm{Fc}^{+}$-ssDNA and $\mathrm{Fc}^{+}$-dsDNA than the free $\mathrm{Fc}^{+}$. Much greater decrease in the peak current upon addition of dsDNA indicated that dsDNA processed higher affinity to $\mathrm{Fc}^{+}$than ssDNA.

After the self-assembled monolayer of 2-mercaptoethylamine was formed on the gold electrode, the couple of redox peaks decreased. The cathodic peak current decreased by $26.3 \%$ (curve B in Fig. 2), indicative of the hindrance of the monolayer to the diffusion of $\mathrm{Fc}^{+}$molecules to the electrode surface in the electrode process. However, the peak currents increased again after the monolayer was derivatized with yeast ssDNA in the presence of water-soluble EDC as coupling reagent.

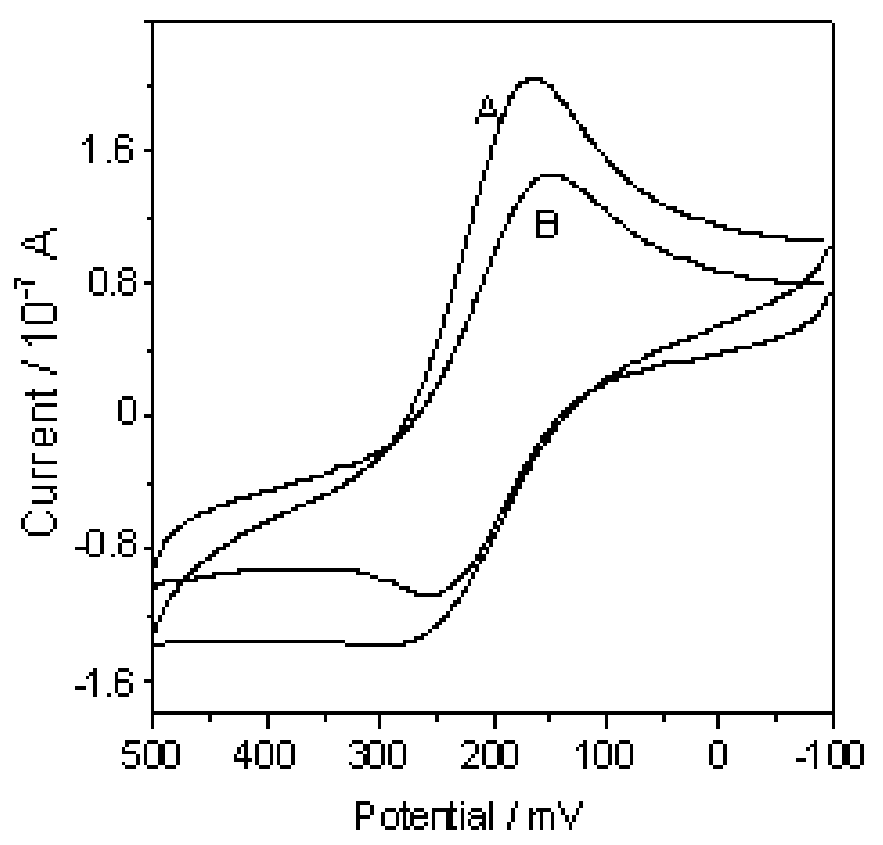

Figure 2. Cyclic voltammograms of $0.4 \mathrm{mM} \mathrm{FcPF}_{6}$ at bare gold (A) and $\mathrm{SAM} / \mathrm{Au}(\mathrm{B})$ electrodes at $200 \mathrm{mV} \mathrm{s}^{-1}$.

The increase in peak current resulted from the interaction of immobilized ssDNA with $\mathrm{Fc}^{+}$species, which made more $\mathrm{Fc}^{+}$species be reduced at the electrode surface. The cyclic voltammetric data were listed in Table 2. At dsDNA/SAM/Au, the peak currents increased further (Fig. 3), thus, the immobilized dsDNA also processed a higher affinity to $\mathrm{Fc}^{+}$than the immobilized ssDNA. 
Table 1. Cathodic peak current of $0.4 \mathrm{mM} \mathrm{FcPF}_{6}$ at $\mathrm{Au}$ electrode upon addition of $0.5 \mathrm{mg} \mathrm{ml}^{-1} \mathrm{ssDNA}$ or dsDNA.

\begin{tabular}{lcc}
\hline Solution & $i_{\mathrm{pc}} / \mu \mathrm{A}$ & Decrease of $i_{\mathrm{pc}}$ \\
\hline $\mathrm{FcPF}_{6}$ & $0.19 \pm 0.02$ & \\
$\mathrm{FcPF}_{6}+\mathrm{ssDNA}$ & $0.16 \pm 0.01$ & $15.8 \%$ \\
$\mathrm{FcPF}_{6}+$ dsDNA & $0.11 \pm 0.01$ & $42.1 \%$ \\
\hline
\end{tabular}

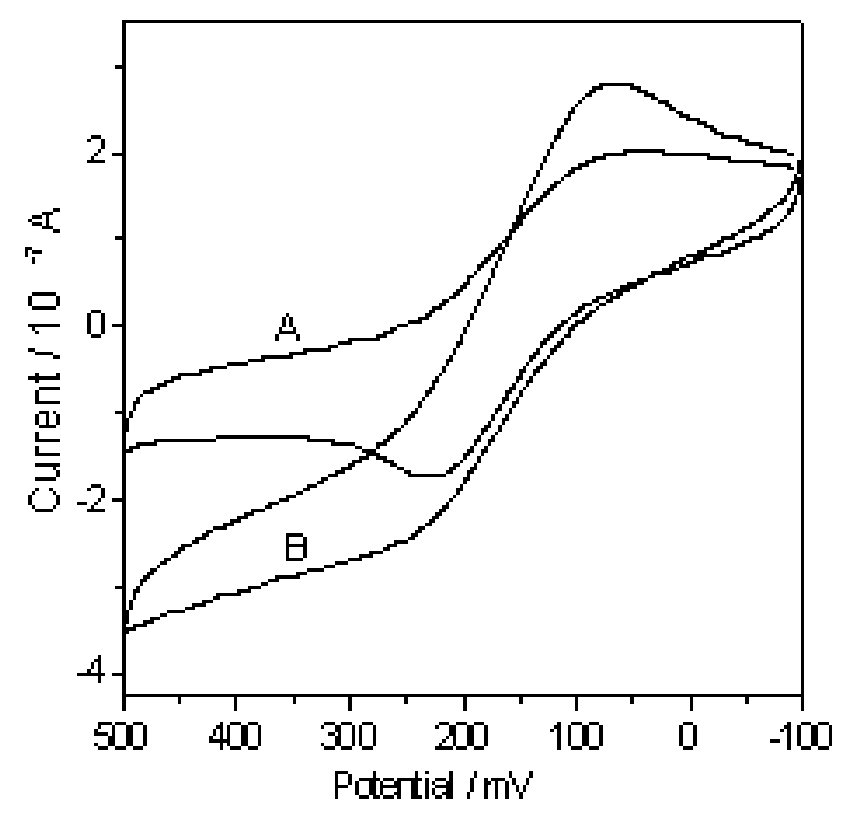

Figure 3. Cyclic voltammograms of $0.4 \mathrm{mM} \mathrm{M} \mathrm{FcPF}_{6}$ at ssDNA/SAM/Au (A) and dsDNA/SAM/Au (B) electrodes at $200 \mathrm{mV} \mathrm{s}^{-1}$.

Table 2. Cyclic voltammetric data of $0.4 \mathrm{mM} \mathrm{FcPF}_{6}$ at $\mathrm{Au}, \mathrm{SAM} / \mathrm{Au}, \mathrm{ssDNA} / \mathrm{SAM} / \mathrm{Au}$ and dsDNA/SAM/Au electrodes at $200 \mathrm{mV} \mathrm{s}^{-1}$.

\begin{tabular}{lcccc}
\hline Electrodes & $i_{\mathrm{pc}} / \mu \mathrm{A}$ & $E_{\mathrm{pc}} / \mathrm{mV}$ & $\begin{array}{c}\text { Increase of } i_{\mathrm{pc}} \\
\text { to prior step }\end{array}$ & $\begin{array}{c}E_{\mathrm{pc}} \text { change to } \\
\mathrm{SAM} / \mathrm{Au} / \mathrm{mV}\end{array}$ \\
\hline $\mathrm{Au}$ & $0.19 \pm 0.02$ & +164 & & \\
$\mathrm{SAM} / \mathrm{Au}$ & $0.14 \pm 0.01$ & +148 & & \\
$\mathrm{ssDNA} / \mathrm{SAM} / \mathrm{Au}$ & $0.17 \pm 0.02$ & +83 & $21.4 \%$ & $-65 \mathrm{mV}$ \\
$\mathrm{dsDNA} / \mathrm{SAM} / \mathrm{Au}$ & $0.33 \pm 0.02$ & +60 & $94.1 \%$ & $-86 \mathrm{mV}$ \\
\hline
\end{tabular}




\section{Adsorption constants of $\mathrm{Fc}^{+}$at ssDNA and dsDNA modified gold electrodes}

The cyclic voltammograms of $\mathrm{Fc}^{+}$at different concentrations at the ssDNA/Au electrode were shown in Fig. 4. With an increasing $\mathrm{Fc}^{+}$concentration, the peak current increased and then trended towards a maximum value. The plot of the peak current vs. $\mathrm{FcPF}_{6}$ concentration showed an expected shape of Langmuir adsorption (inset in Fig. 4).

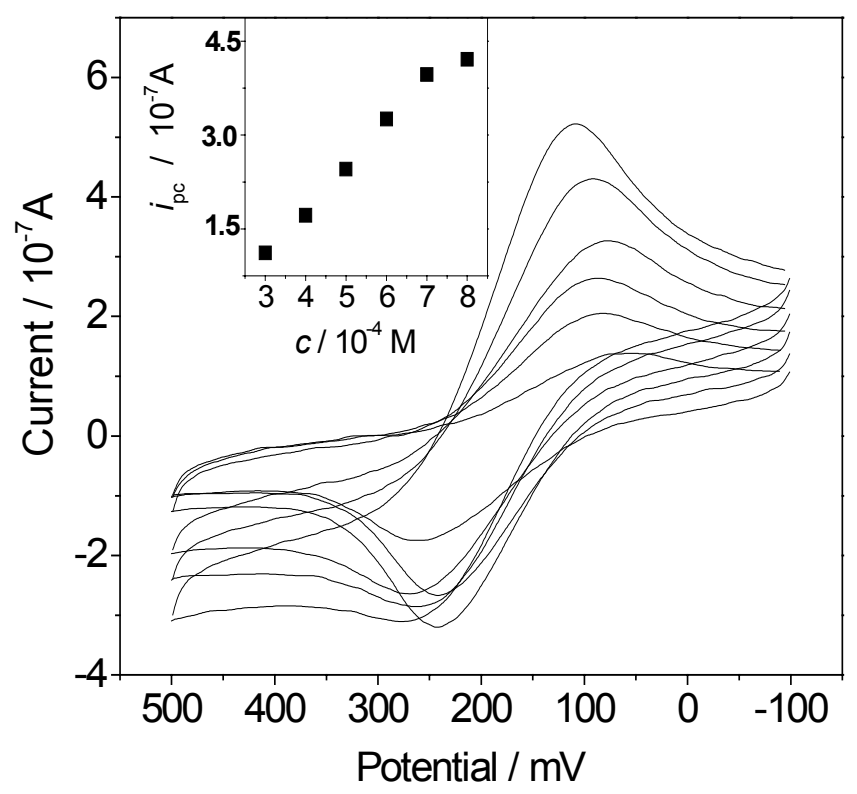

Figure 4. Cyclic voltammograms of $0.3,0.4,0.5,0.6,0.7$ and $0.8 \mathrm{mM} \mathrm{FcPF}_{6}$ (from internal to external) at ssDNA/SAM/Au at $200 \mathrm{mV} \mathrm{s}^{-1}$. Inset: plot of $i_{\mathrm{pc}} v s$. concentration of $\mathrm{Fc}^{+}$.

Similarly, the cyclic voltammogram of $\mathrm{Fc}^{+}$at the dsDNA/Au electrode showed the same behavior. Thus, the adsorption thermodynamics followed the equation:

$$
\frac{c}{i_{p c}}=\frac{1}{K i_{p c, \max }}+\frac{c}{i_{p c, \text { max }}}
$$

where $i_{\mathrm{pc} \text {,max }}$ and $K$ is the maximum cathodic peak current and the adsorption constant of $\mathrm{Fc}^{+}$at ssDNA/SAM/Au or dsDNA/SAM/Au, respectively. From the slope and intercept of plot of $c / i_{\mathrm{pc}}$ vs. $c$, the adsorption constant, $K$, can be obtained. The adsorption constants of $\mathrm{Fc}^{+}$at the ssDNA/SAM/Au and dsDNA/SAM/Au electrodes were calculated to be $(3.38 \pm 0.04) \times 10^{3} \mathrm{M}^{-1}$ and $(2.02 \pm 0.02) \times 10^{4} \mathrm{M}^{-1}$, respectively. The adsorption constant of $\mathrm{Fc}^{+}$at the dsDNA / SAM / Au electrode was about six times that at ssDNA / SAM / Au electrode due to its stronger affinity to $\mathrm{Fc}^{+}$. The different adsorption constants of $\mathrm{Fc}^{+}$at ssDNA/Au and dsDNA/Au indicated that the complex of $\mathrm{Fc}^{+}$with dsDNA was more stable than that with ssDNA, which might result from the different interaction modes for the formation of $\mathrm{Fc}^{+}$-ssDNA and $\mathrm{Fc}^{+}$-dsDNA. 
Supermolecular interaction model of $\mathrm{Fc}^{+}$with yeast $\mathrm{DNA}$

Generally, small molecules are bound to the DNA double helix by three binding modes: electrostatic binding, groove binding and intercalative binding. One accepted point is that small molecules have some extent selectivity when binding with DNA by the latter two modes. The electrostatic binding is the only model by which small molecules can interact with both ssDNA and dsDNA. The binding properties depend on the steric structures and charge of small molecules. In general, planarity is suggested to be the most important feature needed for efficient intercalators. $\mathrm{Fc}^{+}$is a three-dimensional compound with cyclopentadienyl as ligand, which linked to $\mathrm{Fe}^{3+}$ through six $\pi$ electrons. Its thickness is relatively large and the inner distance between two rings is $0.336 \mathrm{~nm}$, while the distance between two base pairs is only $0.34 \mathrm{~nm}$ in the DNA double helix. Therefore, $\mathrm{Fc}^{+}$cannot intercalate into the DNA double helix. However, $\mathrm{Fc}^{+}$has a conjugated system and may interact with dsDNA in a supermolecular way along the grooves of dsDNA by $\pi$-electron conjugation.

The UV spectra of $\mathrm{FcPF}_{6}$ at different concentrations of dsDNA are shown in Fig. 5. The maximum absorption intensity of $\mathrm{FcPF}_{6}$ decreased upon addition of dsDNA, while the maximum absorption wavelength of $619 \mathrm{~nm}$ did not change. In other words, no red shift was observed. This phenomenon excluded the probability of intercalative binding of $\mathrm{Fc}^{+}$with dsDNA, because the decrease of the maximum absorption intensity and red shift of its wavelength are two notable characters of the UV spectrum when small molecules intercalate into the DNA double helix.

The ionic strength of solution influences the electrostatic interaction between small molecules and the phosphate framework of DNA, which makes the peak potential or formal potential of the small molecule change greatly. The effect of ionic strength on the formal potential of $\mathrm{Fc}^{+}$is shown in Fig. 6 . The ionic strength was changed by adding $\mathrm{NaCl}$ into $\mathrm{pH} 8.0$ buffer containing $10 \mathrm{mM}$ Tris, $1.0 \mathrm{mM}$ EDTA, $0.4 \mathrm{mM} \mathrm{M} \mathrm{FcPF}_{6}$ and $0.5 \mathrm{mg} \mathrm{ml}^{-1}$ dsDNA. With an increasing $\mathrm{NaCl}$ concentration, the formal potential of $\mathrm{Fc}^{+}$was retained at $216 \pm 1 \mathrm{mV}$, which was the same as that of $\mathrm{Fc}^{+}$at a bare gold electrode. Thus, the electrostatic interaction model between $\mathrm{Fc}^{+}$and dsDNA in solution could also be excluded, and it could be concluded that the interaction model between $\mathrm{Fc}^{+}$and dsDNA in solution might be a groove binding. The peak potential is supposed to have a positive shift when electroactive molecules intercalate into the DNA helix immobilized on an electrode surface, while a distinct negative shift can be observed when electrostatic binding happens [31-33]. As shown in Table 2, there was a negative shift of $-65 \mathrm{mV}$ during the interaction between $\mathrm{Fc}^{+}$and ssDNA/SAM/Au, while the value was $-86 \mathrm{mV}$ at the dsDNA/SAM/Au. Furthermore, both peaks or formal potentials of $\mathrm{Fc}^{+}$at these electrodes depended on the ionic strength. With increasing ionic strength, the cathodic peaks shifted to a more negative potential, indicative of a prevention to the reduction of $\mathrm{Fc}^{+}$and the interaction between $\mathrm{Fc}^{+}$ and the immobilized ssDNA or dsDNA due to the adsorption of $\mathrm{Na}^{+}$. Thus, the interaction between $\mathrm{Fc}^{+}$ and the immobilized ssDNA or dsDNA was mainly an electrostatic mechanism. At the same time, $\mathrm{Fc}^{+}$ might be aggregated at the dsDNA/SAM/Au in close contact along the groove of the DNA double helix, as that observed in solution. 


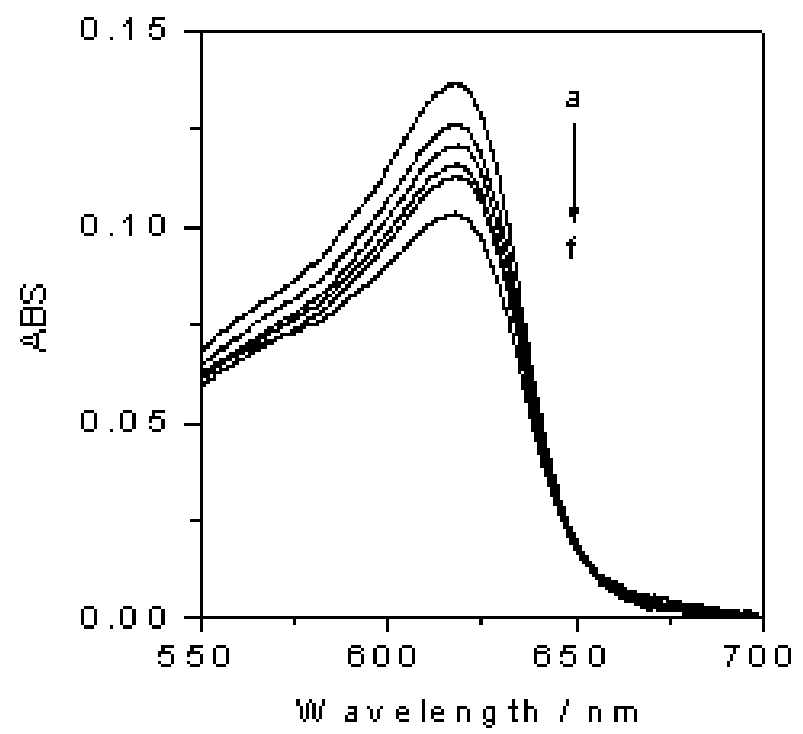

Figure 5. UV spectra of $0.5 \mathrm{mM} \mathrm{M} \mathrm{FcPF}_{6}$ in different dsDNA concentrations of $0,20,40$, 60, 80 and $100 \mu \mathrm{g} \mathrm{ml}^{-1}$ from (a) to (f).

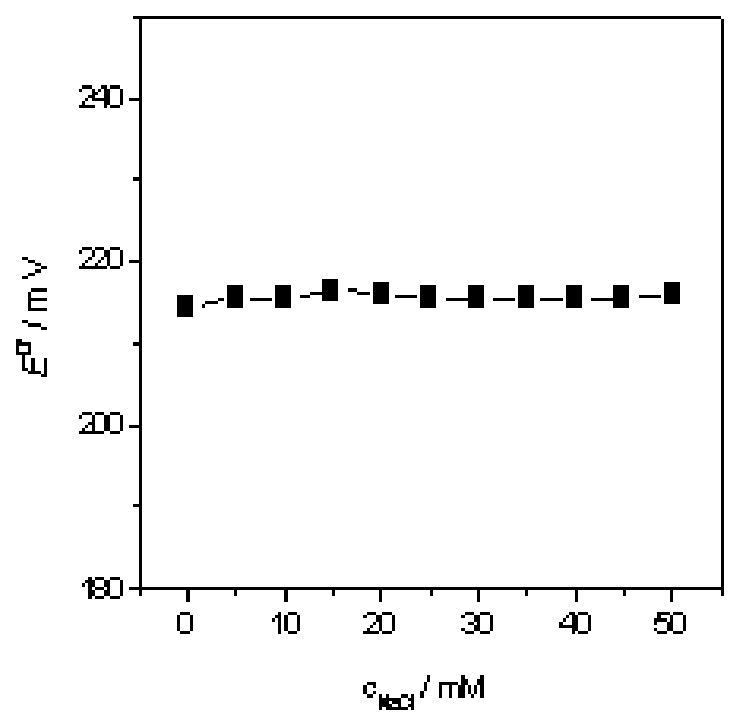

Figure 6. Plot of $E^{0^{\prime}}$ of $\mathrm{Fc}^{+}$measured at the bare gold electrode at $200 \mathrm{mV} \mathrm{s}^{-1}$ in presence of $0.5 \mathrm{mg} \mathrm{ml}^{-1}$ dsDNA vs $c_{\mathrm{NaCl}}$.

\section{Double-layer capacitance at electrode interface}

The double-layer capacitances were determined with cyclic voltammetry. The cyclic voltammograms of these electrodes between +0.40 and $+0.60 \mathrm{~V}$ were recorded in a $1.0 \mathrm{~mol} / \mathrm{L} \mathrm{KNO}_{3}$ solution. The charging current densities $\left(j_{c}\right)$ were measured at $+0.50 \mathrm{~V}$ at different scan rates $\left(v<100 \mathrm{mV} \mathrm{s}^{-1}\right)$. The slope of plot of $j_{c} v s . v$ is the double-layer capacitance. The values of the obtained double-layer capacitances at a bare $\mathrm{Au}, \mathrm{SAM} / \mathrm{Au}$ and ssDNA/SAM/Au electrodes were 15.8, 4.2 and $37.8 \mu \mathrm{F} \mathrm{cm}$, 
respectively. The double-layer capacitance at SAM/Au was lower than that at bare Au electrode due to a low dielectric constant of the monolayer. The ssDNA/SAM/Au electrode showed a higher double-layer capacitance than both bare $\mathrm{Au}$ and SAM/Au electrodes due to the presence of lots of charged groups in the phosphate framework of DNA. This result indicated that ssDNA had been immobilized on the electrode surface by the phosphoramidate bond between the 5 '-terminal phosphate group of ssDNA and the amine group of the 2-mercaptoethylamine monolayer in presence of EDC.

\section{Electrochemical response of the DNA sensor}

Fig. 2 shows the cyclic voltammogram of $0.4 \mathrm{mM} \mathrm{FcPF}_{6}$ at the SAM/Au electrode at $200 \mathrm{mV} \mathrm{s}^{-1}$. The peak-to-peak separation was about $98 \mathrm{mV}$. The peak currents were proportional to the scan rate. The plot of $\log i_{\mathrm{p}} v s . \log v$ gave a slope of 0.50 , showing a diffusion-controlled electrode process. After the monolayer was derivatized with yeast ssDNA in the presence of water-soluble EDC to produce the ssDNA/SAM/Au electrode, the cathodic peak current of $\mathrm{Fc}^{+}$increased by $21.4 \%$ (Fig. 3). As control, when the SAM/Au electrode was treated with the same ssDNA solution without presence of EDC, the cyclic voltammogram gave no significant change in both peak current and potential. The peak current increase of $\mathrm{Fc}^{+}$at the ssDNA/SAM/Au electrode was due to the change of the electrode process. The plot of $\log i_{\mathrm{p}} v s . \log v$ displayed a slope of 0.56 that resulted from the participation of adsorbed $\mathrm{Fc}^{+}$in the reaction process. The adsorption of $\mathrm{Fc}^{+}$at the ssDNA/SAM/Au electrode came from the supermolecular interaction of $\mathrm{Fc}^{+}$with the immobilized yeast ssDNA.

After the ssDNA/SAM/Au electrode was hybridized with cDNA in the hybridization buffer solution to form dsDNA/SAM/Au, the cyclic voltammogram of $\mathrm{Fc}^{+}$showed a cathodic peak current increase of 94.1\% when compared with that at ssDNA/SAM/Au. In comparison with that at the SAM/Au, the cathodic peak current increased by $136 \%$, indicating that more $\mathrm{Fc}^{+}$species were reduced at the electrode surface due to a higher affinity of dsDNA/SAM/Au to $\mathrm{Fc}^{+}$than ssDNA/SAM/Au. The plot of $\log i_{\mathrm{p}} v s . \log v$ at the dsDNA/SAM/Au electrode gave a slope of 0.91 , near to the theoretical value of 1 for a surface-controlled electrode process. Thus, upon hybridization more $\mathrm{Fc}^{+}$species were bound to the surface by both electrostatic and groove bindings with the immobilized dsDNA. The electrode reaction was mainly surface-controlled.

As control, the ssDNA/SAM/Au electrode was incubated in buffer solution containing calf thymus ssDNA (with the different sequence from yeast DNA). After the same treatment process as that of hybridization, the cyclic voltammogram of $\mathrm{Fc}^{+}$at the treated electrode gave the redox peak currents and potentials similar to those at the ssDNA/SAM/Au before incubated, though a change of the charge current was observed due to the heating treatment. Thus, the contribution of nonspecific binding of calf thymus ssDNA and hybridization of immobilized yeast ssDNA with calf thymus ssDNA during the treatment process could be ignored. These results provided a method to recognize the hybridization of yeast ssDNA and to produce a kind of efficient DNA biosensor for the sequence detection of complementary yeast DNA. 


\section{Conclusions}

The device described in this paper provides a simple method to recognize the complementary yeast DNA sequence, using $\mathrm{Fc}^{+}$as an electroactive indicator based on the different affinity abilities of $\mathrm{Fc}^{+}$ with ssDNA and dsDNA. The interaction model of $\mathrm{Fc}^{+}$with dsDNA in solution is a groove binding, while the model of $\mathrm{Fc}^{+}$with immobilized dsDNA is mainly an electrostatic binding. This work uses native yeast DNA probes to prepare the DNA biosensor. The native probes are more liable to be acquired than synthetic oligonucleotides, thus, the method is more convenient in the research field of biological genetics and clinical medicine. This kind of DNA biosensor has a strong potential to be used in the yeast species recognition and the quantitative analysis of specific-sequence yeast DNA. It would be a significant step towards a DNA microarray system and DNA chip technique.

\section{Acknowledgments}

This project was supported by the National Natural Science Foundation of China (No.20275017, 90206037), the Specialized Research Funds for the Excellent Young Teachers from Chinese Ministry of Education, the Science Foundation of Jiangsu (No.BS2001063) and the Key Project of Cancer Institute of Jiangsu Province.

\section{References}

1. Caruso, F.; Rodda, E.; Furlong, D.N. Quartz crystal microbalance study of DNA immobilization and hybridization for nucleic acid sensor development. Anal. Chem. 1997, 69, 2043.

2. Wang, J.; Fermandes, J.R.; Kubota, L.T. Polishable and renewable DNA hybridization biosensors. Anal. Chem. 1998, 70, 3699.

3. Berggren, C.; Stalhandske, P.; Brundell, J.; Johansson, G. A feasibility study of a capacitive biosensor for direct detection of DNA hybridization. Electroanal. 1999, 11, 156.

4. Ivnitski, D.; Abdel-Hamid, I.; Atanasov, P.; Wilkins, E.; Stricker, S. Application of electrochemical biosensors for detection of food pathogenic bacteria. Electroanal. 2000, 12, 317.

5. Wang, J.; Rivas, G.; Cai, X.; Palecek, E.; Nielsen, P.; Shiraishi, H.; Dontha, N.; Luo, D.; Parrado, C.; Chicharro, M.; Farias, P.A.M.; Valera, F.S., Grant, D.H.; Ozsoz, M.; Flair, M.N. DNA electrochemical biosensors for environmental monitoring. A review. Anal. Chim. Acta 1997, 341, 1.

6. Hashimoto, K.; Ito, K.; Ishimori, Y. Novel DNA sensor for electrochemical gene detection. Anal. Chim. Acta 1994, 286, 219.

7. Girotti, S.; Ferri, E.; Ghini, S. Direct quantitative chemiluminescent assays for the detection of viral DNA. Anal. Chim. Acta 1991, 255, 387. 
8. Balakin, K.V.; Korshun, V.A.; Mikhalev, I.I.; Maleev, G.V.; Malakhov, A.D.; Prokhorenko, I.A.; Berlin, Y.A. Conjugates of oligonucleotides with polyaromatic fluorophores as promising DNA probes. Biosensors \& Bioelectronics 1998, 13, 771.

9. Zhang, G.J.; Zhou, Y.K.; Yuan, J.W.; Ren S. A chemiluminescence fiber-optic biosensor for detection of DNA hybridization. Anal. Lett. 1999, 32, 2725.

10. Wang, J.; Rivas, G.; Cai, X.H.; Chicharro, M.; Parrado, C.; Dontha, N.; Begleiter, A.; Mowat, M.; Palecek, E.; Nielsen, P.E. Detection of point mutation in the $p 53$ gene using a peptide nucleic acid biosensor. Anal. Chim. Acta 1997, 344, 111.

11. Zhao, Y.D.; Pang, D.W.; Shen, H.; Wang, Z.L.; Cheng, J.K.; Dai, H.P. DNA-modified electrodes; Part 4: Optimization of covalent immobilization of DNA on self-assembled monolayer. Talanta 1999, 49, 751.

12. Hashimoto, K.; Ito, K.; Ishimori, Y. Novel DNA sensor for electrochemical gene detection. Anal. Chim. Acta 1994, 286, 219.

13. Zhao, Y.D.; Pang, D.W.; Wang, Z.L.; Cheng, J.K.; Qi, Y.P. DNA-modified electrodes. Part 2. Electrochemical characterization of gold electrodes modified with DNA. J. Electroanal. Chem. 1997, 431, 203.

14. Liu, X.J.; Farmerie, W.; Schuster, S.; Tan, W.H. Molecular beacons for DNA biosensors with micrometer to submicrometer dimensions. Anal. Biochem. 2000, 283, 56.

15. Xu, C.; Cai, H.; Xu, Q.; He, P.G.; Fang, Y.Z. Characterization of single-stranded DNA on chitosan-modified electrode and its application to the sequence-specific DNA detection. Fresen. $J$ Anal. Chem. 2001, 369, 428.

16. Steel, A.B.; Herne, T.M.; Tarlov, M.J. Electrostatic interactions of redox cations with surface-immobilized and solution DNA. Bioconjug. Chem. 1999, 10, 419.

17. Sun, X.Y.; He, P.G.; Liu, S.H.; Ye, J.N.; Fang, Y.Z. Immobilization of single-stranded deoxyribonucleic acid on gold electrode with self-assembled aminoethanethiol monolayer for DNA electrochemical sensor applications. Talata 1998, 47, 487.

18. Berney, H.; West, J.; Haefele, E.; Alderman, J.; Lane, W.; Collins, J.K. A DNA diagnostic biosensor: development, characterization and performance. Sensors and Actuators B 2000, 68, 100.

19. Hagenstrom, H.; Esplandiu, M.J.; Kolb, D.M. Functionalized self-assembled alkanethiol monolayers on Au(III) electrodes: 2. Silver electrodeposition. Langmuir 2001 17, 839.

20. Millan, K.M.; Mikkelsen, S.R. Sequence-selective biosensor for DNA based on electroactive hybridization indicators. Anal. Chem. 1993, 65, 2317.

21. Hashimoto, K.; Ito, K.; Ishimori, Y. Sequence-specific gene detection with a gold electrode modified with DNA probes and electrochemically sensor. Anal. Chem. 1994, 66, 3830. 
22. Mishima, Y.; Motonaka, J.; Ikeda, S. Utilization of an osmium complex as a sequence recognizing material for DNA-immobilized electrochemical sensor. Anal. Chim. Acta 1997, 345, 45.

23. Ontko, A.C.; Armistead, P.M.; Kircus, S.R.; Thorp, H.H. Electrochemical detection of single-stranded DNA using polymer-modified electrodes. Inorg. Chem. 1999, 38, 1842.

24. Erdem, A.; Kerman, K.; Meric, B.; Akarca, Y.S.; Ozsoz, M. DNA electrochemical biosensor for the detection of short DNA sequences related to the hepatitis B virus. Electroanal. 1999, 11, 586.

25. Fan, C.H.; Li, G.X.; Gu, Q.R.; Zhu, J.Q.; Zhu, D.X. Electrochemical detection of cecropin CM4 gene by single stranded probe and cysteine modified god electrode. Anal. Lett. 2000, 33, 1479.

26. Takenaka, S.; Ihara, T.; Takagi, M. Bis-9-acridinyl derivative containing a viologen linker chain: Electrochemically active intercalator for reversible labeling of DNA. J. Chem. Soc., Chem.

Commun. 1990, 1485.

27. Kerman, K.; Ozkan, D.; Kara, P.; Meric, B.; Gooding, J.J.; Ozsoz M. Voltammetric determination of DNA hybridization using methylene blue and self-assembled alkanethiol monolayer on gold electrodes. Anal. Chim. Acta 2002, 462, 39.

28. Cai, H.; Xu, C.; He, P.G.; Fang, Y.Z. Colloid Au-enhanced DNA immobilization for the electrochemical detection of sequence-specific DNA. J. Electroanal. Chem. 2001, 510, 78.

29. Xu, C.; Cai, H.; He, P.G.; Fang, Y.Z. Electrochemical detection of sequence-specific DNA using a DNA probe labeled with aminoferrocene and chitosan modified electrode immobilized with ssDNA. Analyst 2001, 126, 62.

30. Oesch, U.; Janata, J. Electrochemical study of gold electrodes with anodic oxide films-I. Formation and reduction behavior of anodic oxides on gold. Electrochim. Acta 1983, 28, 1237.

31. Carter, M.T.; Rodriguez, M.; Bard A.J. Voltammetric studies of the interaction of metal chelates with DNA. 2. Tris-chelated complexes of cobalt(III) and ion(II) with 1,10-phenanthroline and 2,2'-bipyridine. J. Am. Chem. Soc. 1989, 111, 8901.

32. Carter, M.T.; Bard A.J. Voltammetric studies of the interaction of tris(1,10-phenanthroline)cobalt(III) with DNA. J. Am. Chem. Soc. 1987, 109, 7528.

33. Rodriguez, M.; Bard A.J. Electrochemical studies of the interaction of metal chelates with DNA. 4. Voltammetric and electrogenerated chemiluminescent studies of the interaction of tris(2,2'-bipyridine)osmium(II) with DNA. Anal. Chem. 1990, 62, 2658.

(C) 2004 by MDPI (http://www.mdpi.org). Reproduction is permitted for noncommercial purposes. 